ARTICLE

DOI: 10.1057/s41599-018-0141-5

\title{
The Grand Projet politics of an urban age: urban megaprojects in Asia and Europe
}

\author{
Naomi C. Hanakata ${ }^{1} \&$ Anna Gasco ${ }^{1}$
}

\begin{abstract}
This paper presents a comprehensive study of large-scale, master-planned urban developments in Asia and Europe. Increasing in numbers all over the world since the 1980's, these urban mega-projects-here referred to as Grands Projets-have become major drivers of urban intensification. Set forth to actuate urban renewal or to augment city expansion, Grands Projets have become spatial manifestations of cities' larger economic and political agendas. In their development process, they have triggered a change in the urban condition beyond the very boundaries of their sites. As such, they offer a productive means of investigating current urban trends in a globally connected form of concentrated urbanisation. This research, based at the ETH-Future Cities Laboratory (FCL) in Singapore, examines eight case studies in Asia and Europe through five analytical frames: a project's conception, design, implementation, operation and implications. This approach addresses various spatial and temporal scales within different theoretical and material practices, allowing a comprehensive discussion of Grands Projets within and across varying socio-political contexts. This paper sheds light on the specific urban conditions of Grands Projets despite their global development trends, transnational owners or financing alliances and internationally regulated planning practices. Often dependent on exceptional regulations outside statutory planning procedures, they are subject to context-specific challenges, project-specific briefs and unique configurations of actors and stakeholders, all of which have created different manifestations of Grands Projets in space. This analytical framework, as presented in this paper, will form the basis of a larger comparative endeavour to be completed at a later stage in our work.
\end{abstract}




\section{Introduction}

- he development of Grands Projets is accelerating in scope and speed in different geographical locations around the globe. Studying Grands Projets in a context of shifting planning paradigms and socioeconomic restructuring processes enables us to read them as both physical manifestations of these trends and exceptional measures for the development of new urban districts. This paper summarises preliminary insights drawn from an on-going study of urban megaprojects-here referred to as Grands Projets - in Asia and in Europe. The research project, based at the ETH- FCL in Singapore, examines these forms of urban development as complex production processes operating on multiple scales and temporalities. As such, it inspects the impact and potential that Grand Projets offer their respective urban environments.

This paper presents the analytical framework devised to analyse eight case studies. This approach also forms the basis for an ongoing comparative endeavour. Our framework attempts to capture Grands Projets in consideration of their temporal scope and structural complexity with respect to their geographic locations. Our methodology offers a set of analytical entry points to our selected Grands Projets case studies, which include Downtown Core (Singapore), HafenCity (Hamburg), Kings' Cross (London), La Défense (Paris), Lujiazui (Shanghai), Marunouchi (Tokyo), West Kowloon (Hong Kong) and 22@ (Barcelona) (see Table 1).

These case studies were selected initially with regard to their location, due to our project's base in Asia (FCL Singapore) and Europe (ETH Zurich). Our researcher's given expertise in the urban condition of relevant cities further helped to narrow down the case studies in number. The final selection was made to encompass a broad, historical range of Grands Projets of varying stages of development, approaches and governing structures. Our selection also represents a diverse set of private-public stakeholder configurations independent of geographic locus. This allows us to unsettle assumptions about certain development conditions, such as the assumption that stakeholder affiliation to private or public bodies is inherent to specific sociocultural origins or is determined by certain urban development models or intentions. This association was also questioned by Hogan and others (2012) based on work that examines Asian forms of urbanism and highlighting the often generalised observations derived from case-study work located in a single socio-cultural realm.

The multidimensional complexity of Grands Projets requires a mix of quantitative and qualitative methods. Qualitative methods used in this research range from urban analysis, including detailed fieldwork, to 'semi-structured' interviews with a wide range of different stakeholders. These qualitative methods complement empirical data gathered from government reports, documents released by developing and/or operating agencies, local newsletters, statistical annals and scholarly literature.

\section{The Grand Projet rationale}

'Today, Asian cities are fertile sites, not for following an established pathway or master blueprint, but for a plethora of situated experiments that reinvent what urban norms can count as "global"' (Ong, 2011, p. 2).

Throughout the city's history, large-scale and comprehensively planned projects- Grands Projets-have been initiated, negotiated and implemented around the world. Their impact often extends beyond their site, influencing the equilibrium of a larger urban region. Grands Projets have emerged from different motives, including the need to demonstrate power, increase economic growth, establish a presence in global financial

Table 1 Asian and European case studies

\begin{tabular}{|c|c|c|c|c|c|c|c|c|}
\hline & $\begin{array}{l}\widetilde{N} \\
\underset{(8)}{N} \\
\text { N }\end{array}$ & 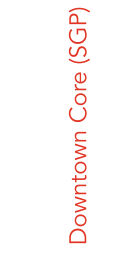 & 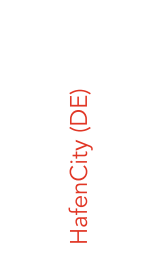 & 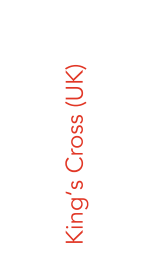 & 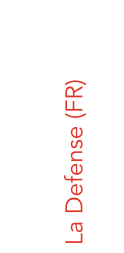 & $\begin{array}{l}\mathcal{Z} \\
\mathcal{U} \\
\bar{N} \\
: \frac{1}{3} \\
3\end{array}$ & 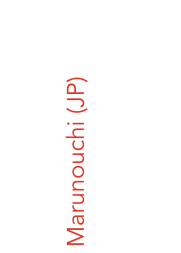 & 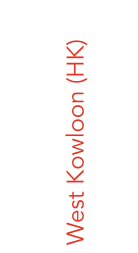 \\
\hline CASE STUDY & $\mathbf{\square}$ & - & $\mathbf{\square}$ & $\mathbf{\square}$ & $\mathbf{\square}$ & - & - & - \\
\hline LOCATION & $\begin{array}{l}\text { Barcelona, } \\
\text { Spain }\end{array}$ & Singapore & $\begin{array}{l}\text { Hamburg, } \\
\text { Germany }\end{array}$ & $\begin{array}{l}\text { London, } \\
\text { UK }\end{array}$ & $\begin{array}{l}\text { Paris, } \\
\text { France }\end{array}$ & $\begin{array}{l}\text { Shanghai, } \\
\text { China }\end{array}$ & $\begin{array}{l}\text { Tokyo, } \\
\text { Japan }\end{array}$ & Hong Kong \\
\hline $\begin{array}{l}\text { STARTING DATE OF } \\
\text { CONSTRUCTION }\end{array}$ & 2001 & 1967 & 2003 & 2007 & 1958 & 1990 & 1890 & 1992 \\
\hline $\begin{array}{r}\text { INITIAL OR MAIN } \\
\text { PROPERTY OWNER }\end{array}$ & Various & City State & City & $\begin{array}{l}\text { King's Cross } \\
\text { Central Ltd. } \\
\text { Partnership }\end{array}$ & State & State & $\begin{array}{l}\text { Mitsubishi } \\
\text { Estate Co., Ltd. }\end{array}$ & State \\
\hline $\begin{array}{l}\text { INITIAL OR MAIN } \\
\text { URBAN PLANNER }\end{array}$ & $\begin{array}{l}\text { City of } \\
\text { Barcelona }\end{array}$ & URA & $\begin{array}{l}\text { KCAP, } \\
\text { ASTOC }\end{array}$ & $\begin{array}{l}\text { Allies Morrison } \\
\text { Porphyrios, } \\
\text { Townshend }\end{array}$ & $\begin{array}{l}\text { Camelot, } \\
\text { Mailly and } \\
\text { Zehrfuss }\end{array}$ & IAURIF & $\begin{array}{l}\text { Mitsubishi } \\
\text { Estate Co., Ltd. }\end{array}$ & $\begin{array}{l}\text { Foster and } \\
\text { Partners, } \\
\text { TFP Farrells }\end{array}$ \\
\hline $\begin{array}{r}\text { INITIAL OR MAIN } \\
\text { PROGRAM }\end{array}$ & Business & Business & $\begin{array}{l}\text { Business } \\
\text { and housing }\end{array}$ & $\begin{array}{l}\text { Commercial } \\
\text { and housing }\end{array}$ & Business & $\begin{array}{l}\text { Finance and } \\
\text { business }\end{array}$ & $\begin{array}{l}\text { Finance and } \\
\text { business }\end{array}$ & $\begin{array}{l}\text { Culture and } \\
\text { retail }\end{array}$ \\
\hline $\begin{array}{r}\text { PROJECT AREA } \\
\text { (ha) }\end{array}$ & 198 & 430 & 127 & 25.8 & 160 & 180 & 128 & 83 \\
\hline
\end{tabular}

Overview of Asian and European case studies 
networks or to expand a city. Grands Projets have strongly influenced urban planning and development processes and the identity of their cities as centres of finance, business, tourism, art and culture.

In the prelude to her reflection on 'worlding cities' with a focus on Asian contexts (Roy and Ong, 2011) Ahiwa Ong writes that "major cities in the developing world have become centres of enormous political investment, economic growth and cultural vitality, and thus have become sites for instantiating their countries' claims to global significance" (Ong, 2011, p. 2). This, we believe, applies to cities in various regions of the world, indifferent of construed boundaries in the global South or what lies 'north' of it. Furthermore, we claim that Grands Projets form vessels for such investment. They are imposed with the simultaneous tasks of rendering spatial qualities of vitality, growth and affluence and achieving global significance.

The term 'Grand Projet' refers to the attempts of the French political elite of the Mitterrand era to enhance Frances's role in art, culture, politics and the economy through the provision of contemporary civic buildings, parks and monuments in Paris between 1981 and 1998. Although the complexity and size of our cases are of a much larger scale than the Grandes Operations d'Architecture et d'Urbanisme, ${ }^{1}$ their logic, ambition and impact on the urban condition show some similarities. Paris's Grands Projets were the outcome of planning competitions that often resulted in the selection of foreign (st-)architects to change the city's image through modern architectural interventions. The majority of Mitterrand's Grands Projets raised controversies for their megalomaniac illustration of power and their cost overruns financed by taxpayer money. After their completion, however, projects such as the Arab World Institute, the Ministry of Finance and the Bibliothèque Nationale contributed to the regeneration of derelict areas in the eastern side of Paris along the Seine, which led to a shift in public acceptance over time. While we use the term Grand Projet in our research as a productive analogy, we are aware of its contextual and scalar shortcomings.

It is this notion of a reified gesture of power inherent in the French Grand Projet that we intend to take forward in our research. In doing so, we qualify our subject of study in contrast to more neutral terms, such as 'urban megaproject,' and make the question of power a constituting element. In the context of our research, we further define the Grand Projet as a large-scale, comprehensively planned development project that has a distinct underlying vision and is realised under the oversight of the same authority, independent of whether or not this authority is represented by single or multiple entities. Our definition is less determined by a price tag (Altshuler and Luberoff, 2003; Marshall, 2003), iconic design or public character (Altshuler and Luberoff, 2003); it is not limited to a certain type of business model or speculative scheme (Swyngedouw et al. 2002; Shatkin, 2011).

Determined by an instantiation of power, a Grand Projet's aim is to transform a city's urban development trajectory, ranging from economic condition to functional focus and the city's image on a global scale. A Grand Projet is closely aligned with the dynamics of existing centralities and forms a new centre for activities and employment in the metropolitan region. Many of our case studies form important nodes in local and regional transport networks. The need for infrastructural upgrades have, in many cases, been the main driver of large-scale interventions in the city's fabric, confirming Flyvbjerg's assessment of these projects as 'central to the new politics of distance because infrastructure is increasingly being built as megaprojects' (2003, p. 3). With that, Grands Projets become points of conversion of abstract and physical space: they are (newly) constructed centralities and locations within a particular hegemonic realm, which exercises control over its urban territory and beyond.
Since the 1980's, large-scale urban development projects have increased in number and speed. They have become vehicles for developing new urban districts, particularly in places with limited land resources and an increasing population. At the same time, Grands Projets have been criticised as spatially exclusive, regulation-excepting projects. They are commonly described as overly top-down and non-transparent in their political organisation, conception, design and implementation processes. Their oftentimes mono-functional outsets are seen as targeting the demands and supply of an (increasingly cosmopolitan) urban elite, enabling "residents to realise their potential as actors in a global economy" (Shatkin, 2011, p. 77) while condoning socioeconomic polarisation and political-economic exclusion.

The investment partnerships carrying the realisation of such projects are increasingly relying on private funds and global networks. Today, in Asia as well as in Europe, even when local money finances the construction of new urban projects, a global knowledge transfer regarding the design, planning and management of Grands Projets becomes the core attribute of these processes. At the same time, the economic scale of contemporary megaprojects, in some cases, compromises national household budgets with a risk of failure that might be transnationalised but not reduced (Merrow et al., 1988). Studying Grands Projets as key elements in urbanisation processes may therefore hold answers to some of the emerging challenges related to the future of our cities and their local, regional and global implications.

\section{Introducing a spatial focus to the study of urban megaprojects}

Concurrent to the increase of Grands Projets in number and size, their phenomenon and relevance have been increasingly discussed in the academic world. Primarily in the realm of governance-related studies, the topic has raised interest as it serves as a vehicle for discussing ongoing urban restructuring processes. Research projects dedicated to the subject have, however, created self-imposed limitations by focusing either on case studies from Europe and North America (Swyngedouw et al., 2002; Fainstein, 2008; Savini and Salet, 2017) or Asia (Shatkin, 2011; Marshall, 2015). Other scholarly works have confronted projects from different political systems and socio-cultural contexts but presented the different geographic insights next to each other rather than engaging them in a comparative conversation (del Cerro, 2013). One early insightful discussion is offered by Swyngedouw, Moulaert and Rodigues in their comparative research of large-scale urban development projects in the context of neoliberal policies in Europe (2002; Moulaert et al., 2003). Considering nine projects in European cities of varying size, the research focuses on the exceptional position these cases occupy in the local planning context and their relation to strategies of economic promotion on the basis of inter-city based competitive restructuring and novel forms of private-public institutional bodies. In their research, Swyngedouw et al. proclaim that an "increasing fragmentation of competencies and responsibilities" is a significant development in policy-making and planning of urban megaprojects (2002, p. 578). This fragmentation, they argue, allows for greater mobilisation of resources and large, collaborative stakeholder configurations; at the same time, a democratic deficit leads to the exclusion of certain actors from the decision-making process.

In later research, Susan Fainstein investigates the role of private-public partnerships in European and American urban projects and confronts their outsets and societal ambitions. She concludes that benefits arising from these partnerships, however, are creating added financial value for themselves rather than contributing to a better urban quality (Fainstein, 2008). Gavin 
Shatkin,Trevor Hogan and Tim Bunnell contribute a longoverdue introduction of Asian megaprojects to the discussion (Shatkin, 2011; Hogan et al., 2012). Shatkin focuses on the role of these projects as reference models in the urban development trajectory of rapidly urbanising cities in Asia. He recognises the role of the private sector as particularly key in this process, describing its shift from a mere facilitator to a central decisive actor in the planning, development and regulation of urban space (Shatkin, 2011).

These insights into the ongoing study of large-scale urban development projects are formative for our investigation and help us to set our focus on two aspects with which we hope to enrich the debate. We focus our study on Grands Projets as a spatialising practice and the material transformation of large-scale urban development projects on the ground. This dimension has been implied in existing discussions, but the way in which institutional shifts, planning schemes and strategies, and implementation mechanisms have shaped the urban form and defined the quality of spaces have received little attention thus far. By looking at the material outcome, its dynamics, potentials and challenges, and identifying links to the respective institutional frameworks these are embedded in, we hope to provide insights into the significance of these dimensions in decision-making processes and planning schemes.

For this investigation, we devised five analytical frames: 'conception,' 'design,' 'implementation,' 'operation' and 'implication.' Analysing our case studies through these frames allows us first and foremost to discuss Grands Projets in width, from early to advanced development stages, enabling us to address the various institutional interdependencies reflected in space. Furthermore, it allows us to deeply examine the way in which an idea for a project was developed (conception), the masterplans or building codes that capture the regulatory framework for a project (design), the type of institutional partnerships that decides on the 'when' and 'how' (implementation and operation), and the way a project impacts urban condition beyond the boundaries of its site on a regional and global scale (implications).

The conception and discussion of these five frames, which provide a common narrative structure throughout our case studies, form the central part of this paper. At a second stage, we will take a comparative perspective on large-scale urban developments across territorial divides, different governmental structures and planning cultures. These initial frames will form an entry point for this future research; comparing our case studies within these frames rather than against the projects as a whole enables us to disclose similarities beyond contextual differences (Robinson, 2011).

The following discussion of each frame draws from three case studies only due to limited space in this paper. The frame itself, however, has been conceptualised in conversation with all eight case studies. The five frames are listed with the eight cases studies under Table 2. The cases discussed in this paper have a grey background (Table 2).

\section{Five analytical frames for analysis}

Conception. The initial phase of a project, predating any design or feasibility study, reveals initial ideas, primary drivers and project aim in a broader socio-political context. It is at this stage that the main objectives-though likely to evolve-are conceived to set the tone for a project's development logic. An investigation of this early stage allows us to derive key insights into the sociopolitical, economic and/or ideological mission a project is set forth to accomplish. In the study of our diverse cases, we have identified three broader development logics:

a. Modernisation: production of a post-industrial city and demonstration of a city's or country's advancement by implementing new knowledge and technologies, strongly linked to attempts of 'westernisation' in Asian projects;

b. Urban Renewal: urban development to revitalise areas, often in central areas coupled with newly available land or outdated functional zones within the existing city fabric;

c. Urban Expansion: urban development to relieve pressure in the city and increase urban territory, sometimes involving land reclamation and often occurring in the periphery of the 'old city centre,' resulting in a significant increase in built-up land.

These three development logics do not define a project trajectory exclusively, but in combination with other factors, such as stakeholder, design and managerial practices, they additionally constitute planning schemes, mechanisms of implementations and operations.

Marunouchi in Tokyo, for example, was initiated when the city (and country) had just been opened up to external trade and influences after being isolated for nearly 200 years. In order to explore latest 'urban development trends,' several missions were sent to Europe under the new Meiji government and ordered to bring back knowledge of modern architecture and urban planning. Marunouchi, a 120-hectare site, located between the imperial palace and the old commercial centre of the city, had been used as a military exercise ground and offered itself as a testbed for these new ideas brought to the Japanese capital. Under the guidance of Western planners, distinctly European ideas of what a modern city should look like were realised in and around the area. Driven by a private developer, Mitsubishi, Marunouchi was established as the city's new business centre. This ambition marked the site as an important moment in the emerging structure of capitalist life. The business headquarters of Mitsubishi, a conglomerate of key drivers in Japan's industrialisation process, and others created a centre of capital and control within the Marunouchi development.

In Paris, post-war economic restructuring and growth posed spatial challenges that the historic city could not meet. In order to protect the city centre and expand its functions for the service sector, the 138-ha site of La Défense was chosen by the French government to provide new office spaces and a modern steel-andglass antipode. Planned from the 1950's onwards, La Défense was the first comprehensively designed, large-scale business district built in Europe. Located at the western end of Paris's historical axis starting at the Palais Royal, the planning of this new area was heavily influenced by the modern vision of the functional city conceptualised in the Athens Charter of 1941: a spatial division of different programmes with high-rise offices and residential blocks, which, in the case of La Défense, were stitched together by a large pedestrian deck hosting necessary transport and service infrastructures beneath. As a formal break with the urban fabric of the city, La Défense presented the start of a new planning approach and radically different architectural typologies in the European city.

In both cases, the project conception marks a particular moment in time-post-isolation, post-war-and the beginning of an era. This is reflected in a new understanding of the city for which the Grand Projet lends itself as a breadboard construction to put these ideas into practice.

The Grand Projet of West Kowloon is comprised of multiple projects of varying intention with different development timelines tied together by a retro-fitted transport network. As a corollary, it is motivated by converging forces resulting from 'the Handover' of Hong Kong to become a Special Administrative Region (SAR) of the People's Republic China (PRC). Built on reclaimed land across the Victoria Harbour from Hong Kong Island, the strategically located project began as an infrastructural 


\section{Table 2 Overview of five analytical frames for analysis with the case studies discussed indicated (shaded in grey)}

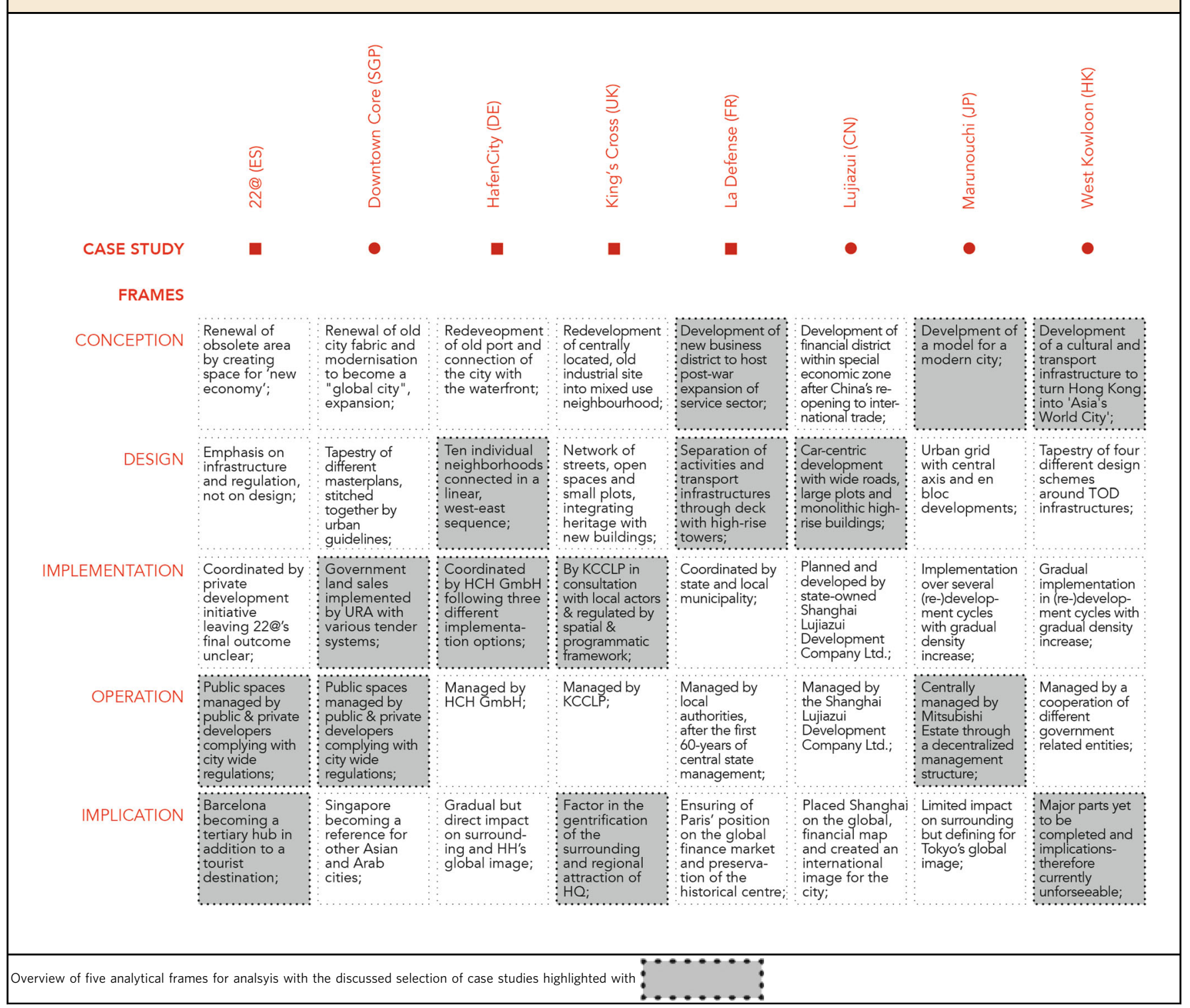

development connecting Hong Kong Island with the new Chek Lap Kok Airport in the 1990s. The current state of the project comprises (a) the transit-oriented development of Kowloon Station; (b) the Express Railway Link (XRL) Station connecting Hong Kong to Guangzhou in the PRC; and (c) the West Kowloon Cultural District (WKCD) in the southern waterfront area. While parts of West Kowloon, including the XRL Station and the WKCD's Palace Museum, have come to symbolise what Hong Kong citizens regard as the growing intrusion of the PRC's central government in the SAR, these projects reveal the SAR government's role in soliciting and facilitating the central government's presence and authority in Hong Kong. WKCD's implementation and operation also reflect the SAR government and its affiliated elites' desire in being 'Asia's World City.' The related branding efforts are supported by the recruitment of international star architects for the WKCD masterplan and selected buildings and the hiring of foreign curators who have little connection to local cultural producers and are seen as further bypassing and alienating the public (Chu, 2010).

Studying Grands Projets in their conception allows us to understand their initial scopes, drivers, incentives and context of space and time. Within the three cases identified, we have also observed that development logics are very much dynamic and undergo modification over time. An important intention within all our cases is the aspect of urban (re-)branding, the change or creation of a city's image on the global stage. This aim is often tied to other place-making strategies that focus on competitive advantages of a project and/or city: financially branded cities such as Hong Kong strive for an image as a cultural hub, while culturally branded cities like Paris aim at expanding their 'urban service scope.' This contingency is also indicative of a general programme diversification, which we observed in all Grands Projets: an effort is made to create an increasingly diverse urban condition, which is, however, always folded into the logics of project development laid out in a Grand Projet's conception.

Design. The underlying design scheme of any Grand Projet marks a decisive moment of negotiation and is a central tool for exercising control. Potentially conflicting ideas and priorities of involved stakeholders must be concerted and translated into a spatial scenario. Proposed design schemes are increasingly informed by a global knowledge exchange of urban typologies, spatial requirements and efficiency standards via internationally 
active developers and planning offices. Investigating a project's design allows us to look at the mechanisms that underpin the production of space and to understand the materialised outcome of a project.

The realised scheme for La Défense was planned and implemented by the Public Planning Institute of La Défense (Établissement public pour l'aménagement de la région de la Défense: EPAD) from 1958 onwards. The first masterplan scheme devised by Camelot, Mailly and Zehrfuss in 1964 proposed a functional city with a multi-level deck to contain all transport and service infrastructures within the site, a design that allowed for a pedestrian exclusive open-space plaza with high-rise offices and residential blocks. The masterplan posed several challenges, such as a physical border that disconnected the surrounding communities from the business district. While initially planned in an almost exclusive conversation between the central government and the EPAD, the role of the surrounding municipalities in the planning and management of La Défense has been steadily increasing. The adaptation of the deck, the central design element, however, poses an on-going economic and integration challenge to the planning body (Établissement public d'aménagement de la Défense Seine Arche: EPADESA, until December 2017).

The masterplan for Lujiazui was selected in a competition held in 1992. Participating offices included Richard Rogers Partnership, Dominique Perrault Architecture, Massimiliano Fuksas and Toyo Ito \& Associates. Official reasons for selecting the proposal by Richard Rogers Partnership claimed that it reflected more traditional, Western urban planning principles in the volumetric composition and circular road scheme (Xue et al. 2011, p. 10). The plan, which the Shanghai Urban Planning and Design Institute finally released, showed significant departures from the Richard Rogers Partnership plan, however: while it maintained the central, circular area as a park and the central axis, it mainly catered to the corporate headquarters of multinational corporations, reflecting the client's economic aspirations. The urban layout with large blocks and wide roads illustrates the dominance of an automobile-centric network, which occupies more than a third of the ground space. Large plots with monolithic high-rise buildings are set back from the streets and form a coarse urban grain. The main challenges of the implemented scheme are the quality and connectivity of public spaces, which reduce pedestrian accessible space to less than fifteen percent. While singular, iconic buildings within the site are well connected to the road and transport network, the connectivity between sites poses challenges for people who live or work in Lujiazui. This is one of the site's spatial conditions which, we argue, implies that the priority within the design scheme was placed on the development's modern appearance and imposing skyline rather than on its functionality and ground quality.

In the case of HafenCity in Hamburg, the winning scheme was chosen in an international competition in 1999. This competition was preceded by an in-depth development study, which identified the potential and challenges of the 127-hectare site as an extension of the historic city centre. The winning scheme of this competition was a skeleton plan by KCAP and ASTOC Architects and Planners that served as a framework meant to be updated over the course of a twenty-year implementation period and concretised with several smaller-scale urban design competitions. This design skeleton emphasised the development of ten neighbourhoods within the site, which had varying programmatic focus and were composed of diverse architectural typologies. However, all of them drew from close proximity to the waterfront and the visual connection to the historic port and city in order to create distinct urban qualities despite several design challenges, such as flood protection and noise pollution.
This brief overview of the design of some of our Grands Projets case studies already reveals many differences in the way initial design schemes were produced, their importance to the project development and their actual spatial qualities. The proposed design schemes can roughly be categorised into projects that either work with a spatially unique feature of high iconic value or those with a more generic spatial frame of strategic openness that allows for greater flexibility in the site's interpretation and future development. While the process of producing these documents can be more or less inclusive, the nature of the underlying documents is yet another matter: whether a formal masterplan (as in the case of Lujiazui), a detailed masterplan brief (King's Cross), a framework plan (HafenCity) or a set of building regulations (Barcelona), these documents reflect varying legal requirements and design approaches toward more formal plans, on the one hand, and more open-ended plans with increased capacity to adapt to changing urban needs on the other hand.

Implementation. The implementation of a Grand Projet provides a crucial moment for analysis within the project development, where 'grand' visions are confronted with the realpolitik of local governments and established practices. The following explorations of our case studies within the analytical frame of 'implementation' focus on the governing structure that is instrumental in the implementation process, the means and procedures chosen to realise a project and the temporal frame for project realisation.

In the case of King's Cross in London, the local authoritiesmainly the borough of Camden-along with other public stakeholders and the private developer Argent collaborated in the site's redevelopment. Camden played an active role in negotiations, engaging simultaneously in the role of 'enabler, partner and client' (Swyngedouw, Moulaert and Rodriguez, 2002, p. 566) to secure new affordable homes, civic and community facilities, public spaces, employment and training centres. In addition, a long community consultation helped to develop a fairly cohesively supported agreement for the area's future. The new scheme was nevertheless criticised for its lack of real social and regenerative benefits to the wider community (Edwards, 2010, 2015; Campkin, 2013), as well as for how the consultation was carried out (Imrie, 2009). A key strategy to support the physical and social integration of the new development within its larger surroundings was the phasing. Early stages focused on the development of the public realm; streets and open spaces were realised first and supported by various temporary uses for selected plots yet to be developed, such as a community garden and a swimming pond. These measures created opportunities for interactions between local users and neighbouring residents and facilitated the site's gradual reintegration into public life.

In the case of Singapore, the Urban Redevelopment Authority (URA) - a centralised national urban planning authority-is the primary executing body in the implementation of urban plans and strategies for the Downtown Core, a 430-ha site. While advised by an international team of consultants, it has been able to realise design schemes for the area in a cohesive way since all old as well as newly reclaimed land belongs to the government, with the exception of some areas on freehold, which are sold for 999 years. Since the beginning of the project in the 1960s, a stable central administration and continuously updated urban agenda allowed for the urban planning practice to evolve in a way that permits location and project-specific response by either prioritising economic revenue models, the iconic value of a project, or a compromise between the two. Variants of these tender systems resulted in a distinctive implementation model geared towards creating added urban value. 
The case of HafenCity provides the example of a special institutional format initiated by the city to facilitate the project's realisation. The Gesellschaft für Hafen und Standortentwicklung a body established in 1997, was renamed in 2004 as the HafenCity Hamburg $\mathrm{GmbH}$. This new body, was meant to be equipped with the necessary expertise for the development to operate at an internationally competitive level. It is owned by the City of Hamburg and responsible for the 'special city and port fund' as well as the sales and development of the project at large. It holds in-depth, local knowledge with which it manages its entrusted land asset. In doing so, it has great liberty in defining the mechanisms, strategies and priorities: while various public and private actors are involved at different stages in the form of advisory boards, award committees and evaluation panels, the company remains the main authority in decision-making during the implementation process. Based on the spatial skeleton plan envisioned by its planners, the HafenCity Hamburg $\mathrm{GmbH}$ developed an elaborate tendering scheme for the realisation of smaller individual projects. This allows for the Grand Projet to be implemented in separate stages with different, spatially targeted specifications that tie the development together and simultaneously provide the opportunity for projects to respond typologically and programmatically to changing needs and requirements over time.

Looking at the way Grands Projets are implemented in different cities around the globe, we can discern various similarities in the governing structure of these projects and the legal frameworks and procedures chosen to realise them. While the role of the government itself varies greatly from one case to another, the private sector plays an important role in all of them. This role ranges from Grands Projets as new opportunities for private investment to tailoring them to the needs of private, corporative tenants to, in the more extreme case, establishing special, private institutions in charge of project development. These bodies are formally private entities built upon a strong backing of local public authorities. As such, they present decentralised forms of governance and market-led development while relying on stateissued exceptional rules and conditions to facilitate implementation of Grands Projets. This is also an observation that Swyngedouw et al. make in their study of European large-scale urban developments. Their analysis of an increasingly 'fragmented and pluralistic mode of urban governance' implies a 'redefinition of roles played by local authorities' (Swyngedouw et al., 2002, p. 566) and also helps address the changing conditions of negotiations over space, rights of access and priorities in the realisation processes of Grands Projets.

Less surprising is the fact that due to their size and complexity, all Grands Projets require extensive time for realisation. The temporal dimension of implementation processes, however, differs significantly between case studies in importance and approach: looking at our eight case studies in Asia and Europe, we observe that the implementation over time is either a central part of the project development strategy or the unintended result of other procedures. Interestingly, both scenarios are linked to the project's initial conception and/or continuity of the institutional setting within which the project framework was established; the way a project is implemented is therefore telling of whether a Grand Projet is meant to produce a specific envisioned image or rather contribute to an urban transformation in a certain way.

Operation. Our fourth analytical frame is the 'operation' of Grands Projets. Through this frame we analyse projects' daily management and actors involved. Operation is crucial to quality of and access to open spaces as well as tenant selection and their possible roles in estate management. Hence, this frame enables us to understand the power relations amongst stakeholders in the managerial process and the priorities in this process, which reflect specific management cultures and spatial programmatic results. The following section focuses on the public realm since it is a key element directly influenced by management practices within Grands Projets.

In the case of Singapore, several governmental agencies (including the URA) and multiple private stakeholders manage the public realm in the Downtown Core area. Open spaces managed by private developers are subject to approvals and fulfilment of the primary aim to attract commercial footfall. Those managed by URA primarily cater to national and international events in realisation of the government's vision for Marina Bay as the 'Bay for Events and National Celebrations.' These spaces are likewise subjected to URA's general regulations to ensure that events do not disrupt social or racial harmony or pose risks to public health, order or safety (URA Singapore, 2017). This condition of multiple yet often intertwined institutions in charge ${ }^{2}$ reflects the specificity and complexity of the country's multi-tiered governmental organisation and the many agendas of the Downtown Core development.

In the case of Marunouchi in Tokyo, following a restructuring of Mitsubishi after the Second World War, Mitsubishi Estate continued as the area's central privately-operated planning authority. In 1988, a new governing body was founded in response to growing public and state interest and criticism of future plans for the area. Today, this body, the Council for Area Development and Management of Otemach, iMarunouchi, andYurakucho, consists of different property owners and represents a wider range of interest. In the subsequent years, further governing subsidiaries were added and dedicated to the programming of public space in the area, provision of a greater diversity of activities and sustainability efforts. However, all of these subsidiaries remained under the directive power of Mitsubishi Estate. In addition, a coherent merchandising strategy was put in place with the 'Marunouchi Card' to provide advantages to commercial facilities within Mitsubishi Estate properties. This is one of many measures by Mitsubishi Estate that support a coherent experience and specific place-making strategy for the area, which help the company regulate access to space and exercise control by subjecting the area to its own regulations.

In the case of 22@, the management of open spaces depends on land ownership. There are three different types of open space tenure in the area: (a) publicly-owned accessible spaces (provided through the requirement of $18 \mathrm{~m}^{2}$ of open space for every $100 \mathrm{~m}^{2}$ of social housing GFA); (b) privately-owned and publicly accessible spaces; and (c) privately-owned spaces inaccessible to the public. The first type (a) is owned by the City Council and managed by the Municipal Institute of Parks and Gardens. The regulations that define the usage of this space do not differ from those of publicly-owned accessible spaces in Barcelona. The second kind of open space (b) is owned and managed by private owners. They have, however, the so-called 'right of way' granted by the City Council. This legal right allows the public to pass through private property. The motivation for this is to increase public accessibility of open spaces and ensure a continuous open space network. While both the ownership and management of these spaces remain in the hands of private property owners, the public administration has specific requirements as to how to maintain these spaces. In public perception, however, these spaces usually do not appear any different from the first and second type ( $a$ and b), nor do they restrict use or access in any greater way. Hence, 22@ provides an example in which a coherent quality of open spaces was established despite different operational structures. 
Looking at public space management within Grands Projets enables us to understand the priorities set out by different managerial structures and strategies and the implications they have for users. Despite the proliferation of urban megaprojects and knowledge transfer to support their conceptualisation and implementation, management practices remain largely localised and/or context-dependent. Case studies like Marunouchi or Downtown Core show that a diverse range of stakeholders can contribute to the operational practice of Grands Projets. However, the existence of a single governing body in charge of daily project operations ultimately informs the 'when' and 'how' of this contribution, thus reflecting the hierarchical power structures of Grands Projets.

Implications. Grands Projets are central drivers in the transformation of a city's urban development trajectory, its economic condition and functional focus. The 'implications' of Grands Projets become apparent on different scales and in different dimensions. Grands Projets can function as catalysts for the regeneration of adjacent areas but can also support the change of a city's image on a global scale. In our research, we have analysed and qualified four types of effects-not mutually exclusive-of different scales:

a. Localised effects taking place within Grands Projets themselves. These can be directly sought by the (re-)development strategy but also occur as a result of users' behaviours or changes in economic and political situations.

b. Effects on adjacent neighbourhoods, which undergo changes through the impact of the redeveloped area.

c. Regional effects occurring at a larger scale; through, for example, increased transport connectivity or programmatic intensifications, Grands Projets can change regional urban dynamics.

d. Global effects, taking place when Grands Projets transform the global perception of their city through the production of a specific image in order to fulfil certain aims, such as increased recognition or economic prosperity.

All of these effects can be intended or unintended; however, most of them are not within the direct control of the actual Grand Projet regulatory framework.

In the case of King's Cross in London, rippled effects from the heart of the site towards its surroundings are noticeable with an increase in residential prices on site and within a one and a half kilometers radius (Knight Frank, 2016). While these effects on the surroundings can be seen as proliferating gentrification in the wider area, it is difficult to dissociate this gentrification from the project's central location in the city and the easy access to the transport hub. The surroundings, mainly to the East of the site, had started to change prior to the area's redevelopment (Edwards, 2010), and mainly following the approval of the Channel Tunnel Rail Link Act in 1996, which moved Britain's first high-speed railway from London Waterloo rail station to St. Pancras. More recent localised effects on site are becoming apparent in 2018, although only half of the project is developed so far: Granary Square has become a favourite playground for children and a popular location for open-air gatherings and events. Subsequently, intensive public use of open spaces in the area may lead to a limitation of car accessibility; in fact, the King's Cross Central Limited Partnership - the partnership of landowners-has mentioned the wish to close Granary Square to motor traffic between King's Boulevard and Stable Street to ensure a safe pedestrian environment (Alderson, 2017).

The case of 22@ portrays manifold implications. On a regional scale, the project was initiated to prevent companies leaving
Barcelona by providing a modern tertiary hub for knowledge intensive activities within the city region. The Catalan city has since been ranked the most innovative metropolis in Spain (2016-2017), the fifth in Europe and the 13th worldwide.22@ has strengthened Barcelona's global emphasis on the importance of knowledge and technology intensive companies. 22@ has also capped urban restructuring of the northeast side of Barcelona, creating a new centrality via the provision of 93'000 new jobs, 1'600 new housing units, $15 \mathrm{~km}$ of urbanised streets with highquality infrastructures and several research and educational institutions that bolster the transfer of knowledge between industry and society. The city's subsequent global attention has in turn reinforced Barcelona's status as a leading tourist destination. The development of 22@ has also led to a transformation of its surrounding sites, such as Glories Square, which is currently being restructured as an urban park surrounded by tertiary cultural buildings.

West Kowloon in Honk Kong illustrates the tensions that often arise when Grands Projets proliferate change on a regional scale. In this case, these are the effects of its transport-oriented development, namely the airport link and high-speed rail station to China, as well as its Cultural District. Hong Kong's MTR Corporation and local private developers have turned Kowloon Station into a prestigious landmark through a marketing strategy of high-end exclusive residences located above a luxury shopping mall. Fifteen years after Kowloon Station was conceived, the site has become one of the most premium estate areas in Hong Kong. Especially given the future adjacent XRL Station, which will connect passengers to China, the residences above Kowloon Station are the preferred target of Mainland Chinese investors, surpassing the more traditional high-class housing estates located on Hong Kong Island (such as the Mid-levels). Since 2015, highend speculative housing project-still largely unoccupied todayhave been developed on the periphery of West Kowloon, tabling on the future success of proximity to the XRL Station and Cultural District.

Grands Projets present multiple implications for their cities. These implications are not mono-causal but rather the result of changing economic situations, branding strategies and other factors. Ultimately, looking at the qualities and scales of implications allows us to see the different ways in which Grands Projets alter current urban dynamics and reconfigure existing power structures. Grands Projets disrupt as much as they instigate these dynamics and structures. Furthermore, their physical form, financing models or managerial practices have implications by becoming references for new forms of urban transformation elsewhere. It is the latter that Roy and Ong referred to as an interreferencing' and 'worlding' practice in relation to varying forms of global spatial production (Roy and Ong, 2011).

\section{Conclusion}

The growing number and size of Grands Projets has led to new forms of urban governance, spatial design, production and regulation. In many cases, Grands Projets can be found at the centre of urban restructuring processes and collated efforts to (re-) generate development. Laid out in this way, our research has therefore taken Grands Projets as a moment to investigate current trends in a globally connected form of concentrated urbanisation.

Our five analytical frames do not provide an exhaustive tool for analysis of urban megaprojects; they nevertheless allow us to examine a project in its temporal scope and structural complexity. While we focus on aspects that directly affect spatial practices, it is a context specific reading within our general analytical frames that creates a productive dialogue between Grand Projet development processes across varying geographies. 
In our study, we were able to identify some common trends: over the last three decades the rhetoric with which Grands Projets have been advertised and realised has sway in a broader range of narratives and programmes, now including diverse actors and activities including retail, cultural, educational and entertainment facilities. This has changed the way Grands Projets integrate into urban conditions. In places like Marunouchi in Tokyo or La Défense in Paris, an initially mono-functional business centre has diversified its programme in response to new users and an increasing residential population. Concurrently, recently conceived projects like West Kowloon or King's Cross have promoted themselves as mixed-use districts with a focus on culture or education.

Another observation, however less consistent, has been a shift in the design of projects: rather than devising detailed masterplans, which define the project in its full scope, some Grands Projets now show a more strategic approach. In the case of HafenCity Hamburg, the underlying masterplan does not specify a particular urban scenario but rather focuses on essential spatial elements, areas and phases within the development trajectory. This gives stakeholders the opportunity to adapt to changes and to respond to new needs or ideas that emerge over the course of development. This approach endows projects with a greater capacity to adapt and develop their own logic, but it requires a stable, forward-looking governing structure able to navigate the many 'open' possibilities in a development trajectory.

With regard to their implementation and operation in a global comparative context, Grand Projets show a dependency on exceptional regulations and practices outside the statutory planning procedures to achieve efficient realisation. This is reflected in outsourcing of management and operation affairs from established public planning bodies to specially created ones, which are often able to bypass protracted (planning) submission procedures. This can lead to an exclusion of a wide range of stakeholders as the accountability for a project becomes blurred or appears to be largely in the hands of private developers. Furthermore, the navigation outside common planning procedures and the establishment of special urban development bodies leads to singular and/or localised outcomes. The capacity of these urban projects to indicate a shift in planning practices on a larger scale is therefore limited. Hence, Grands Projets can be seen less as representations of change in local planning systems but more as indicators of competitive restructuring processes in concentrated urban areas on a global scale.

Lastly, due to their potential to revitalise and/or direct the urban development trajectory of a city, Grands Projets have gained high priority in the urban agenda of local stakeholders and have often become central to a reassessment of a city's position in the emerging global economy. Projects like Lujiazui or Downtown Core have been conceptualised to create a globally competitive image for their cities and henceforth have served as the visual reference for what the country was capable of achieving: they have become samples of 'little perfect worlds' of what a city could be, should be or will be. Grands Projets have thus become origins of theorisation rather than merely moments of application or entry points to an understanding of urban development in an interconnected and inter-referenced state. As such, Grands Projets have also become indicative of a globally expanding network of urban development practices, whether via involvement of foreign design and consultancy teams, internationally practicing developers and contractors, cosmopolitan residents, tenants or visitors. Grands Projets are built upon global knowledge transfers within all stages of their developments, but they have also acted as infrastructures for these transfers themselves; they have become centralities for development practices as much as references for projects elsewhere.
Received: 22 November 2017 Accepted: 6 June 2018

Published online: 10 July 2018

\section{Notes}

1 The 'Grandes Operations d'Architecture et d'Urbanisme' included the Louvre Pyramid, the Musée d'Orsay, the Parc de la Villette, the Arab World Institute, the Opéra Bastille, the Grande Arche de La Défense, the Ministry of Finance and finally the Bibliothèque Nationale de France, by far the biggest and most expensive one.

2 Some of the other public spaces managed by different governmental agencies include Marina Reservoir (by Public Utilities Board), Jubilee and Helix Bridge (by Land Transport Authority) and The Float (by SportSG).

\section{References}

Alderson S (2017) Interview of Steve Alderson, Marketing Director at Argent since 2002 (by Anna Gasco)

Altshuler AA, Luberoff D (2003) Mega-projects: the changing politics of urban public investment. Brookings Institution Press and Institute of Land Policy, Washington and Lincoln

Campkin B (2013) Remaking London: decline and regeneration in urban culture. I. B.Tauris, London

del Cerro G (ed.) (2013) Urban megaprojects: a worldwide view. v. Emerald Group Publishing (Research in UrbanSociology, vol 13), New York, NY

Chu C (2010) People power as exception: three controversies of privatisation in post-handover Hong Kong. Urban Stud 47(8):1773-1792

Edwards M (2010) King's Cross: renaissance for whom?. In: Punter J (ed.) Urban design and the British urban renaissance. Routledge London, London

Edwards, M. (2015) King's Cross: the dark side. https://michaeledwards.org.uk/ 2015/04/19/kings-cross-the-dark-side/. Accessed 19 April

Fainstein SS (2008) Mega-projects in New York, London and Amsterdam. Int J Urban Reg Res 32(4):768-785. https://doi.org/10.1111/j.1468-2427. 2008.00826.x

Flyvbjerg B, Bruzelius N, Rothengatter W (2003) Megaprojects and risk: an anatomy of ambition. Cambridge University Press, Cambridge

Hogan T et al. (2012) Asian urbanisms and the privatization of cities. Cities 29 (1):59-63

Imrie R (2009) An exemplar for a sustainable world city: progressive urban change and the redevelopment of King's Cross. In: Imrie R, Lees L, Raco M (eds) Regenerating London: governance, sustainability and community in a global city. Routledge, Abingdon, p 93-111

Knight Frank (2016) Knight Frank-focus on: King's Cross 2016. Knight Frank Research Report. Residential Research. Knight Frank LLP, London. http:// www.knightfrank.com/research

Marshall R (2003) Emerging urbanity: global urban projects in the Asia Pacific Rim. Spon, London

Marshall T (2015) Prisoners of geography: ten maps that explain everything about the world. Scribner, New York, NY

Merrow EW, McDonnell L, Argüden RY (1988) Understanding the outcomes of megaprojects: a quantitative analysis of very large civilian projects. Rand Corp, Santa Monica, CA

Moulaert F, Rodriguez A and Swyngedouw E (2003) The globalized city: economic restructuring and social polarization in European Cities. OUP, Oxford.

Ong A (2011) Introduction worlding cities, or the art of being global. Worlding cities: Asian experiments and the art of being global. Wiley-Blackwell, Chichester, West Sussex; Malden, MA

Robinson J (2011) Cities in a world of cities: the comparative gesture. Int J Urban Reg Res 35(1):1-23. https://doi.org/10.1111/j.1468-2427.2010.00982.x

Roy A, Ong A (2011) Worlding cities: Asian experiments and the art of being global.Wiley-Blackwell, Chichester, West Sussex; Malden, MA

Savini F, Salet W (2017) Planning projects in transition: interventions, regulations and investments. Jovis Berlin, Berlin

Shatkin G (2011) Planning privatopolis: representation and contestation in the development of urban integrated mega-projects. World Cities Asian Exp Art being Glob 41:77

Swyngedouw E, Moulaert F, Rodriguez A (2002) 'Neoliberal urbanization in Europe: large-scale urban development projects and the new urban policy'. Antipode 34(3):542-577

Urban Redevelopment Authority (URA) Singapore (2017) Public space event application. https:/www.ura.gov.sg/Corporate/Get-Involved/Shape-A-DistinctiveCity/Explore-Our-City/Marina-Bay/Event-Application.

Xue CQL, Zhai H, Mitchenere B (2011) Shaping Lujiazui: the formation and building of the CBD in Pudong, Shanghai. J Urban Des 16(2):209-232. https://doi.org/10.1080/13574809.2011.552705 


\section{Data availability}

The research, conducted at the ETH Future Cities Laboratory Singapore (FCL), is based on fieldwork, interviews, and publicly available datasets gathered between September 2015 and November 2017. The data that support the findings of this study are available from the corresponding author upon reasonable request.

\section{Acknowledgements}

The work presented in this paper draws upon the preliminary findings of a three year research project on 'The Grand Projet: Towards Adaptable and Liveable Urban Megaprojects' at the Future Cities Laboratory of the ETH in Singapore. The support of contacts and interview partners for each case study project is gratefully acknowledged.

\section{Additional information}

Competing interests: The authors declare no competing interests.

Reprints and permission information is available online at http://www.nature.com/ reprints
Publisher's note: Springer Nature remains neutral with regard to jurisdictional claims in published maps and institutional affiliations.

\section{(c) (i)}

Open Access This article is licensed under a Creative Commons Attribution 4.0 International License, which permits use, sharing, adaptation, distribution and reproduction in any medium or format, as long as you give appropriate credit to the original author(s) and the source, provide a link to the Creative Commons license, and indicate if changes were made. The images or other third party material in this article are included in the article's Creative Commons license, unless indicated otherwise in a credit line to the material. If material is not included in the article's Creative Commons license and your intended use is not permitted by statutory regulation or exceeds the permitted use, you will need to obtain permission directly from the copyright holder. To view a copy of this license, visit http://creativecommons.org/ licenses/by/4.0/.

(C) The Author(s) 2018 